Research Article

\title{
Pharmacokinetic Comparisons of Mangiferin and Mangiferin Monosodium Salt in Rat Plasma by UPLC-MS/MS
}

\author{
Hongbin Guo, ${ }^{1}$ Mengqiao Chen, ${ }^{1}$ Mengran Li, ${ }^{1}$ Mingye Hu, ${ }^{2}$ Baohua Chen, ${ }^{1}$ \\ and Chengyan Zhou $\mathbb{1}^{1}$ \\ ${ }^{1}$ College of Pharmaceutical Sciences, Key Laboratory of Pharmaceutical Quality Control of Hebei Province, Hebei University, \\ $180 \mathrm{WuSi}$ Road, Lianchi District, Baoding 071002, China \\ ${ }^{2}$ Department Gastroenterol, Wenzhou No. 3 Clinical Institute Affiliated Hospital, Wenzhou Medical University, \\ 57 Canghou Street, Lucheng District, Wenzhou 325000, China
}

Correspondence should be addressed to Chengyan Zhou; xuefanone@163.com

Received 23 June 2019; Revised 15 August 2019; Accepted 31 August 2019; Published 14 November 2019

Academic Editor: Gabriel Navarrete-Vazquez

Copyright ( 2019 Hongbin Guo et al. This is an open access article distributed under the Creative Commons Attribution License, which permits unrestricted use, distribution, and reproduction in any medium, provided the original work is properly cited.

\begin{abstract}
Mangiferin (MG) is an active component in natural medicines, and various studies have been reported on pharmacological effects, but the low solubility and bioavailability of MG limit its wide application. The aim of the present study was to investigate the pharmacokinetic profiles of mangiferin (MG) and mangiferin monosodium salt (MG-Na) in rat plasma by UPLC-MS/MS, which were then compared between the two groups. An appropriate high sensitivity and selectivity ultraperformance liquid chromatography-tandem mass spectrometry (UPLC-MS/MS) method was applied to the comparison of plasma pharmacokinetics in MG and MG-Na using carbamazepine as internal standard (IS). These results showed that there were statistically significant differences in the pharmacokinetic parameters between MG and MG-Na after a single oral administration at $100 \mathrm{mg} / \mathrm{kg}$. When compared with pharmacokinetic parameters of MG, the $\mathrm{AUC}_{(0-t)}, \mathrm{AUC}_{(0-\infty)}, C_{\max }, K_{10}$, and $K_{\mathrm{a}}$ of MG-Na were increased by 5.6-, 5.7-, 20.8-, 8-, and 83.6-fold, while the $T_{\max }$ and CL/F were decreased by 4 - and 5.7-fold $(P<0.001)$, respectively. $t_{1 / 2}$ value showed an increasing trend, but was statistically significant between the two groups. Moreover, the AUC value in the MG-Na group was significantly increased and the relative bioavailability was calculated to be $570 \%$ when compared with that of the MG group. These results suggested that the salification reaction of MG can effectively enhance gastrointestinal absorption and relative bioavailability by improving solubility and membrane permeability.
\end{abstract}

\section{Introduction}

Mangiferin (MG, Figure 1), 1,3,6,7-tetrahydroxyxanthoneC2- $\beta$-D glucoside, is a type of xanthone derivative found in Mangifera indica L., Anemarrhena asphodeloides Bunge, and other plants [1-5]. Recent studies showed that MG has multiple beneficial biological activities, including antidiabetes, antioxidation, antitumor, anti-inflammation, immunoregulation, antipyretic, antibacterial, memory improvement, and prevention of ultraviolet-induced skin aging [6-9]. In our previous studies, we have also established that mangiferin can have protective effects on hyperlipidemia and metabolic and organ functions. In addition, MG is utilized in a series of natural medicines in clinic, and no evidence has been found about MG side effects [10-13].
However, our preliminary studies showed that MG exhibits poor fat solubility and water solubility, which leads to low transmembrane permeability and poor bioavailability. Meantime, the clinical application of MG is greatly restricted due to its poor absorption and bioavailability $[14,15]$. So, in order to improve the bioavailability, biological activity, and clinical application of MG, the structure of MG needs to be modified.

Recently, researchers have carried out a series of structural modifications on MG, such as alkylation reaction, acylation reaction, a salification reaction, and phospholipidation reaction [16]. In particular, a salification reaction is simple and easy during operation and can improve the solubility and compliance of the drug, reduce adverse reactions, facilitate absorption in the gastrointestinal tract, and 


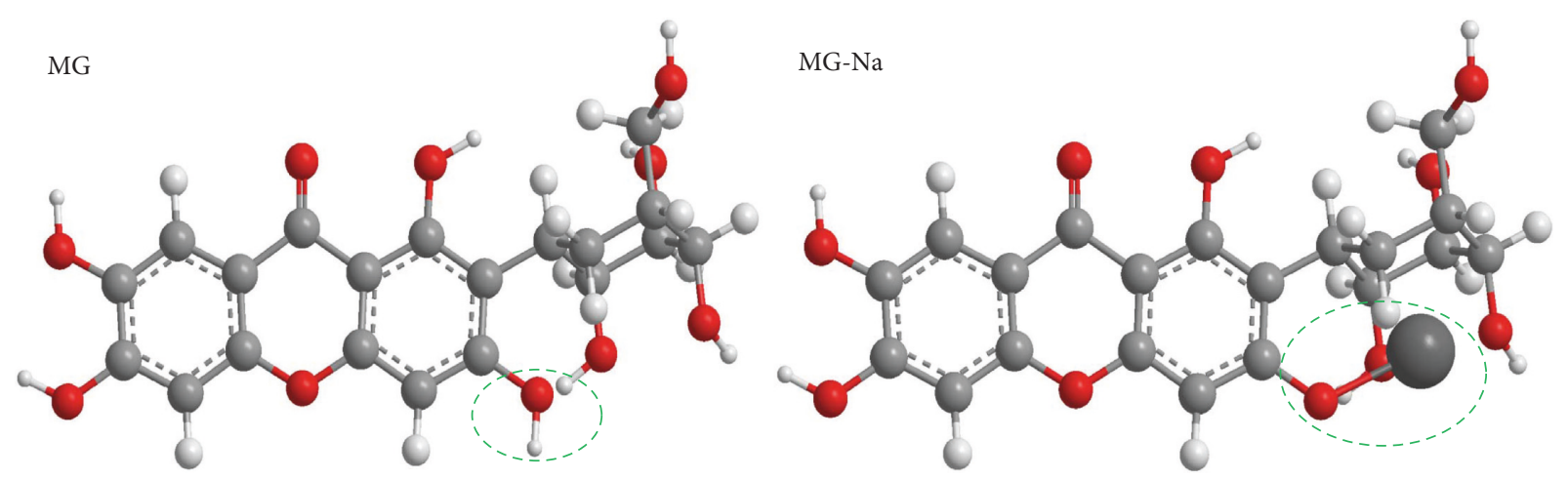

Figure 1: Chemical structure of MG and MG-Na.

increase bioavailability and efficacy. And a salification reaction has been verified and applied in many medicines, such as andrographolide and tanshinol. So, we synthesized the MG monosodium salt (MG-Na, Figure 1) in this study. Researchers found that MG-Na has a uniform and obvious anti-infection effect on pneumococci, Staphylococcus aureus, and Haemophilus influenzae. In addition, recent studies had also confirmed that MG-Na has a better effect than MG on antitussive, expectorant, anti-inflammatory, antioxidant, and antidiabetic effects. The above results suggested that MG-Na can improve the treatment effect when compared with MG [17-21]. Currently, the pharmacokinetics of MG$\mathrm{Na}$ has not been studied. Moreover, pharmacokinetics is a discipline which studies the absorption, distribution, metabolism, excretion, and toxicity of drugs in vivo and also shows the great significance for the development and safety evaluation of drug [22-24].

For further research and development of MG-Na, we systematically studied the pharmacokinetic comparison of $\mathrm{MG}$ and MG-Na rats in vivo in the present study [25]. Firstly, we described an ultraperformance liquid chromatography-tandem mass spectrometry (UPLC-MS/MS) assay for the pharmacokinetic comparison determination of $\mathrm{MG}$ and MG-Na in rats in vivo with carbamazepine as internal standard (IS) [26]. This assay has some merits, such as precise sample preparation, good linearity and specificity, and negligible carryover [27]. Then, the above method was successfully applied to the pharmacokinetic comparison study of MG and MG-Na in rats in vivo in the present study. This is the first study that obtained a systematic view of dissection of the plasma UPLC-MS-based pharmacokinetics of MG-Na as an effective evaluation strategy for absorption and metabolism, which provided the foundation for the clinical application of MG-Na [28, 29].

\section{Experimental}

2.1. Chemicals and Reagents. MG sample $\left(\mathrm{C}_{16} \mathrm{H}_{12} \mathrm{O}_{4}\right.$, purity $>98.00 \%$ ) and MG standard sample (purity $>99.99 \%$ ) were purchased from Chroma Biological Co. Ltd. (Sichuan, China). Carbamazepine $\left(\mathrm{C}_{15} \mathrm{H}_{12} \mathrm{~N}_{2} \mathrm{O}\right.$, IS) was obtained from the National Institutes for Food and Drug Control (Beijing, China). Methanol and acetonitrile (HPLC grade) were purchased from Fisher Scientific (Pittsburgh, PA, USA).
Formic acid of HPLC grade was supplied from Aladdin Industrial Co. Ltd. (Shanghai, China). Acetone $\left(\mathrm{CH}_{3} \mathrm{COCH}_{3}\right)$ and sodium bicarbonate $\left(\mathrm{NaHCO}_{3}\right)$ were purchased from Kermel Chemical Reagent Co. Ltd. (Tianjin, China). Heparin sodium was obtained from Wanbang biochemical Medicine Group Co. Ltd. (Jiangsu, China). Ultrapure water (sensitivity of $18.80 \mathrm{M} \Omega$ ) was prepared by passing distilled water with a Milli-Q system (Millipore, Shanghai, China).

The synthesis and purification of MG-Na were performed in our laboratory involved method (Figure S1) [30]. To the $1.688 \mathrm{~g}$ of $\mathrm{MG}$ in the presence of $55-60^{\circ} \mathrm{C}$ acetone $(20 \mathrm{~mL})$-water $(8 \mathrm{~mL})$ mixed solution was added $5 \%$ $\mathrm{NaHCO}_{3}(22.4 \mathrm{~mL})$ within $15 \mathrm{~min}$ and then further stirred for a clear solution. After, the reaction was quenched with acetone $(120 \mathrm{~mL})$ in order to obtain a yellow thick suspension, and then the yellow thick suspension was filtered and dried at $60^{\circ} \mathrm{C}$ to $1.4529 \mathrm{~g} \mathrm{MG}-\mathrm{Na}(81.81 \%)$. Subsequently, MG-Na was further purified by recrystallization using acetone. The elementary analysis of MG-Na was performed by Elementar vario Micro Cube, Elementar vario EL III Cube, and ICP-MS (Agilent 7700), respectively.

2.2. Animal Experiment. Forty male Sprague Dawley (SD) rats (7 weeks old, weighing $200 \pm 20$ g) and eighty Kunming mice with both sexes ( 7 weeks old, weighing $20 \pm 2 \mathrm{~g}$ ) were provided by the Vital River Laboratory Animal Technology (Beijing, China; certification number: 11400700243083 and 1100111911036181; license no. SCXK (Jing) 20160006 and 20160011). Ethical approval for the experimental protocols was obtained from the Animal Ethical and Welfare Committee (AEWC) of Hebei University (approval number: IACUC-2018045 dated 11/05/2018). All experimental rats were fed one week before the experiment. The rats were housed in polycarbonate cage and kept at constant temperature $\left(23 \pm 2^{\circ} \mathrm{C}\right)$ and relative humidity $(65 \pm 5 \%)$ with a $12 \mathrm{~h}$ light/dark cycle. The rats had free access to standard chow diet and water ad libitum.

In the study, the rats were selected to perform the pharmacokinetic comparisons of MG and MG-Na according to previous reports and $\mathrm{ICH}$ guidelines by European Medicines Agency [31-33]. After a week of acclimatization, experimental rats $(n=20)$ were randomly divided into two 
groups according to average body weight: MG group (MG $(100 \mathrm{mg} / \mathrm{kg}), n=10)$ and MG-Na group (MG-Na $(100 \mathrm{mg} /$ $\mathrm{kg}), n=10)$. The dosage regimen for MG was selected on the basis of previous reports and our preliminary studies [25, 33-35]. After withholding food for 12 hours, the rats were treated by gavage with a single administration according to the above dosage regimen. Water was available ad libitum throughout the experiments. About $500 \mu \mathrm{L}$ blood samples were collected from fossa orbitalis vein puncturing by a capillary tube into heparinized centrifuge tubes at each time point (predose, $5,10,15,30,60,120,180,240,360,480$, $600,720,1440,2160$, and $2880 \mathrm{~min}$ ). Here, the time points were selected to construct the bioavailability curve according to previous reports $[25,34,36,37]$ and our preliminary experiment. The plasma samples were obtained by $3000 \mathrm{rpm}$ centrifugation at $4^{\circ} \mathrm{C}$ for $10 \mathrm{~min}$, and then, the supernatant was stored at $-80^{\circ} \mathrm{C}$ until analysis.

\subsection{Preparations of Calibration Standards and Quality} Control (QC) Samples. The stock solutions of MG and MG$\mathrm{Na}$ were prepared by dissolving accurately weighed quantity of each drug in methanol at the concentration of $0.1 \mathrm{mg} / \mathrm{mL}$. The above standard stock solutions were diluted with methanol to obtain standard working solutions at concentrations of 10.0, 20.0, 50.0, 100.0, 200.0, 500.0, 1000.0, 2000.0, and $6000.0 \mathrm{ng} / \mathrm{mL}$ for MG and MG-Na, respectively. Stock solution for IS was prepared at the concentration of $0.1 \mathrm{mg} /$ $\mathrm{mL}$ in methanol and diluted with methanol to yield the working solution of IS at $100 \mathrm{ng} / \mathrm{mL}$. The calibration standards were prepared by adding a series of $10 \mu \mathrm{L}$ of standard working solutions and $10 \mu \mathrm{L}$ IS of working solutions into $80 \mu \mathrm{L}$ of drug-free blank plasma to obtain plasma samples at concentrations of 1.0, 2.0, 5.0, 10.0, 20.0, 50.0, 100.0, 200.0, and $600.0 \mathrm{ng} / \mathrm{mL}$. The QC samples were also prepared from the stock solution at the low, middle, and high concentrations of 3,160, and $480 \mathrm{ng} / \mathrm{mL}$ [38-40]. All the above solutions were stored at $4^{\circ} \mathrm{C}$, until the analysis.

2.4. Preparations of Plasma Samples. Plasma samples were prepared by adding $10 \mu \mathrm{L}$ of IS and $90 \mu \mathrm{L}$ of blank plasma in the $1.5 \mathrm{~mL}$ polyethylene tube and then vortexing for $3 \mathrm{~min}$. The $300 \mu \mathrm{L}$ acetonitrile was added in the mixture sample by vortexing for $5 \mathrm{~min}$ and then centrifuged for $10 \mathrm{~min}$ at $13,000 \mathrm{rpm} / \mathrm{min}$ at $4^{\circ} \mathrm{C}$ to remove precipitated proteins. And an aliquot of $100 \mu \mathrm{L}$ supernatant was injected into the UPLC-MS/MS system for the analysis.

2.5. Instrumental Conditions. The ultraperformance liquid chromatography (UPLC) system was connected with a Vanquish System (Thermo Scientific, San Jose, CA, USA) which consists of two pumps, a detector, and a sample room. The chromatographic column was ACQUITY UPLC BEHC18 column $(1.7 \mu \mathrm{m}, 2.1 \mathrm{~mm} \times 50 \mathrm{~mm}$; Waters, USA) with the column temperature set at $40^{\circ} \mathrm{C}$, when the chromatographic separation was carried out in the study. The binary mobile solvent was adopted which consists of $0.1 \%$ formic acid solution (A) and acetonitrile (B) to elute MG or MG-Na in program. The following gradient steps were used: $0-1 \mathrm{~min}$ $5 \% \mathrm{~B}, 1-7$ min $5-100 \% \mathrm{~B}, 7-10 \mathrm{~min} 100 \% \mathrm{~B}, 10-10.2 \mathrm{~min}$ $100-5 \% \mathrm{~B}$, and $10.2-12 \mathrm{~min} 5 \% \mathrm{~B}$ and the flow rate was $0.3 \mathrm{~mL} / \mathrm{min}$. The autosampler temperature was maintained at $4^{\circ} \mathrm{C}$, and the injection volume of the sample was $2.0 \mu \mathrm{L}$.

Mass spectrometric detection was performed on a TSQAltis-10265 mass spectrometer (Thermo Scientific, San Jose, CA, USA) equipped with an electrospray ionization interface (ESI). The plasma samples were detected by a TSQ Altis MS/ MS system in the ESI negative ion mode. Following the optimization of mass spectrometric parameters, the positive ion voltage, negative ion voltage, sheath gas, auxiliary gas, sweep gas, ion transfer tube temperature, and vaporizer temperature were set at $3500 \mathrm{~V}, 3500 \mathrm{~V}, 50 \mathrm{Arb}, 23.2 \mathrm{Arb}, 0$ Arb, $52^{\circ} \mathrm{C}$, and $350^{\circ} \mathrm{C}$, respectively. The selective reaction monitoring (SRM) was applied for the detection of MG, MG-Na, and IS transition of $\mathrm{m} / z 421.035 \longrightarrow 301.054$, $421.035 \longrightarrow 301.054$, and $237.062 \longrightarrow 179.054$, respectively.

\subsection{Method Validation}

2.6.1. Selectivity. The specificity was performed by analyzing six different drug-free blank plasma samples, drug-free blank plasma spiked with analytes and IS, and drug-free blank plasma of the rats after oral administration of analytes (MG and MG-Na), respectively. Chromatographic review was carried out to assess the potential endogenous interference, which developed a method can be considered to have acceptable selectivity if no interfering endogenous substances were observed at the retention times of the analytes and IS.

2.6.2. Linearity and Sensitivity. Linear calibration curves in blank plasma were drawn by plotting the peak area ratios $(\mathrm{Y})$ of the analytes (MG and MG-Na) to the IS vs. the concentrations $(X)$ of the standards. By a weighted $\left(1 / X^{2}\right)$ linear regression analysis, the calibration curves were described as $y=a x+b$. The linearity of MG and MG-Na was analyzed by the correlation coefficient means $\left(R^{2} \geq 0.9999\right.$ or better) in the calibration curve. The lower limit of detection (LLOD) was investigated based on at least 3 times of signal-to-noise ratio and the lower limit of quantification (LLOQ) was determined based on at least 10 times of signal-to-noise ratio. The limit of quantification was recognized by the analysis of 6 replicates prepared independently. The relative error (RE) acceptance criterion of each point should be within $\pm 15 \%$ ( $\pm 20 \%$ for the LLOQ).

2.6.3. Precision and Accuracy. The precision and accuracy were analyzed by the QC samples at three concentrations (3, 160 , and $480 \mathrm{ng} / \mathrm{mL}$ ). The intraday and interday precision and accuracy were determined by analyzing six replicates of plasma samples on the same day and three consecutive days, respectively. The standard curve was used to calculate the concentration of each plasma sample on the same day. Furthermore, the precision and accuracy were evaluated by the relative standard deviation (RSD, $<15 \%)$ and $\mathrm{RE}( \pm 15 \%)$, 
respectively. The acceptance criterion of RSD should be less than $15 \%$, and the acceptance standard of RE should be within $\pm 15 \%$.

2.6.4. Extraction Recovery and Matrix Effect. To investigate the extraction recovery and matrix effects, QC samples from 6 replicates at three concentration levels $(3,160$, and $480 \mathrm{ng} /$ $\mathrm{mL}$ ) were analyzed. The extraction recovery of two analytes was analyzed by comparing the peak areas of analytes (MG and MG-Na) spiked before precipitated protein with those of analytes spiked after precipitated protein. And, the matrix effect was measured by comparing the peak of analytes spiked after precipitated protein with those of analytes in reconstitution solution. These procedures were repeated for six replicates at three QC concentration levels, and the results were required to be within $\pm 15 \%$.

2.6.5. Stability. The stability of $\mathrm{MG}$ and $\mathrm{MG}-\mathrm{Na}$ in rat plasma during sample storing and processing procedures was evaluated by six replicates of QC samples under different conditions, such as short-term stability, long-term stability, and freeze-thaw stability. The short-term stability was analyzed after the storage of QC samples exposed to room temperature for $6 \mathrm{~h}, 12 \mathrm{~h}$, and $24 \mathrm{~h}$. The long-term stability was investigated after the storage of QC samples at $-80^{\circ} \mathrm{C}$ for 4 weeks. To evaluate the freeze-thaw stability, the QC samples were measured after three cycles of freeze $\left(-80^{\circ} \mathrm{C}\right)$ and thaw $\left(20^{\circ} \mathrm{C}\right)$.

2.6.6. Dilution Integrity. To evaluate the dilution procedure, the dilution integrity of analytes was performed by four different concentrations of MG and MG-Na diluting a high concentration of plasma samples $(1000 \mathrm{ng} / \mathrm{mL})$ with blank plasma to a low concentration $(10,100$, and $500 \mathrm{ng} / \mathrm{mL})$. The diluted samples were analyzed with six batches by a freshly prepared calibration curve. The RE of each plasma sample should be within $\pm 15 \%$, and the RSD of each plasma sample should not exceed $15 \%$.

2.6.7. Carryover. Carryover of the tested analytes was assessed by injection of drug-free blank plasma samples after injection of the upper limit of quantification (ULOQ, $600 \mathrm{ng} / \mathrm{mL}$ ). The measured peak area should be within $20 \%$ of the MG and MG-Na peak area at the LLOQ level.

2.7. Safety Analyses. The rats $(n=20)$ were selected to perform the safety evaluation. Safety evaluation included animal behavior (walk and sleep), food, water and energy intake, hair, body weight, tissue weight, liver function (ALT, AST, and ALT/AST), liver histopathology, feces, and urine. Safety was evaluated regularly from predose and after dose (4 weeks). All experimental significant abnormal study detection results were performed until resolved or stabilized. In addition, the acute toxicity (such as lethal dose $50\left(\mathrm{LD}_{50}\right)$ and maximum tolerated dose (MTD)) was measured by the method of Nancy et al. and Tong et al. [41, 42], and eighty mice were used in here. The design of the experimental animal numbers was based on the desire to obtain adequate safety data to achieve the objectives of the safety analyses. The study can provide the understanding of the safety and toxicity of MG and MG-Na.

2.8. Data Analysis. According to the above calibration curves, the concentration of drug was calculated in plasma of all rats at each time point. The pharmacokinetic parameters of the analytes (MG and MG-Na) were automatically simulated and calculated by utilizing Drug and Statistics (DAS) 2.0 (Chinese Pharmacological Society). The elimination constant $\left(K_{10}\right)$, terminal elimination half-life $\left(t_{1 / 2}\right)$, absorption constant $\left(K_{\mathrm{a}}\right)$, maximum concentration $\left(C_{\max }\right)$, time to reach $C_{\max }\left(T_{\max }\right)$, area under the plasma concentration-time curve from zero time to last time point of analysis $\left(\mathrm{AUC}_{(0-t)}\right)$, area under the plasma concentrationtime curve from zero time to infinity $\left(\mathrm{AUC}_{(0-\infty)}\right)$, apparent distribution volume $\left(V_{1} / F\right)$, and clearance $(\mathrm{CL} / F)$ of the drug were all determined. The relative bioavailability $(F)$ of $M G$ to MG-Na was calculated by using the following equation:

$$
F=\frac{\mathrm{AUC}_{0-\infty}(\mathrm{MG}-\mathrm{Na})}{\mathrm{AUC}_{0-\infty}(\mathrm{MG})} \times 100 \% \text {. }
$$

The results were presented as mean \pm SD. Statistical analysis between MG and MG-Na groups was statistically analyzed and processed using SPSS 16.0 (Statistical Package for the Social Science) by independent samples $t$-test, and the $P$ value $<0.05$ was suggested to be statistically significant.

\section{Results and Discussions}

3.1. Method Development. Recently, there were several reports on the LC, HPLC, and HPLC-MS analysis of MG in plasma $[43,44]$. However, the majority of HPLC was operated at low sensitivity and selectivity. With the development of high sensitivity and selectivity UPLC-MS/MS technology, TSQ-Altis was applied to this study which based on the triple-quadrupole mass spectrometer offers the advantages of low sample consumption and fast analysis rate to pharmacokinetic study [45]. Chromatographic conditions (column temperature, column type, and binary mobile solvent type) were selected to obtain high selectivity, reduce run time, and optimize peak shape. Acetonitrile rather than methanol was selected as the organic phase because it eluted clean and obtained excellent peak shape [46]. The formic acid solution of $0.1 \%$ was used as the water phase, which resulted in a higher mass response by increasing the degree of ionization. Meantime, there are many general sample pretreatment methods, such as solid-phase extraction, solidphase microextraction, liquid-liquid extraction, and protein precipitation. However, protein precipitation was used in the pretreatment of biological samples due to its simple operation, low time consumption, and high practical value which was also used in this study [47]. The above method was successfully applied to the pharmacokinetic comparison of MG and MG-Na, of which results show that the improvement and application of the method can significantly 
improve the response of MG and MG-Na. Overall, this study is original and practical. Therefore, this study will lay a good foundation for the research and development of $M G$ and MG-Na treatment effect in future.

3.2. Synthesis of $M G-N a$. To investigate the pharmacokinetics of MG-Na, we first performed the synthesis of MG-Na in the present study. MG-Na was synthesized by the reaction of mangiferin with sodium bicarbonate. The product was yellow powder with a yield of $81.81 \%$. The purity of MG-Na was verified by UPLC to be more than $93.50 \%$ and MG-Na was purified to $98.00 \%$. Here, the elementary analysis results of MG-Na showed that Anal. Calcd. for $\mathrm{C}_{19} \mathrm{H}_{17} \mathrm{O}_{11} \mathrm{Na}$ : C, 51.35; H, 3.83; O, 39.64; Na, 5.18\%. Found: C, 51.20; H, 3.23; $\mathrm{O}, 39.87 ; \mathrm{Na}, 5.09 \%$. In addition, our results showed that the water solubility of MG-Na was greatly improved compared with that of the MG in this study.

\subsection{Method Validation}

3.3.1. Selectivity. As shown in Figure S2, no obvious endogenous interference was observed at the retention times for either the MG and MG-Na or the IS in the drug-free plasma sample used for analysis, and we found that the method showed a good specificity in the present study. Representative chromatograms, including a drug-free blank plasma sample, a blank plasma sample spiked with two analytes and IS, and a plasma sample of the rats after oral administration of MG or MG-Na, were obtained. The retention time of these was $2.98 \mathrm{~min}, 2.98 \mathrm{~min}$, and $4.55 \mathrm{~min}$, respectively, under the chromatographic conditions in this study.

3.3.2. Linearity and Sensitivity. The typical equation of calibration curves and linearity ranges for the analytes (MG and MG-Na) are shown in Figure S3, under the selected chromatographic conditions. The correlation coefficients $\left(R^{2}\right)$ of all linear equations were higher than 0.9999 . The equation of MG calibration curves was described as $y=0.0012 x+0.0014$ and $R^{2} \geq 0.9999$. The calibration curves of MG-Na were described as $y=0.0006 x+0.0009$ and $R^{2} \geq 0.9999$. The linearity for MG and MG-Na was obtained in the concentration range of $1.0-600.0 \mathrm{ng} / \mathrm{mL}$. The above results suggested a good linearity within the above-selected concentration range in the drug-free plasma sample. In addition, the LLOQ of MG and MG-Na was $1.0 \mathrm{ng} / \mathrm{mL}$, which can be sufficient for the following pharmacokinetic analysis.

3.3.3. Precision and Accuracy. The results of the precision and accuracy of the methods are shown in Table 1 by the measurement of QC samples (3, 160, and $480 \mathrm{ng} / \mathrm{mL}$ ). The intraday and interday RSD were less than $6.9 \%$, and the intraday and interday RE ranged from $-2.2 \%$ to $7.8 \%$. The above data were within the acceptable limits, which suggested that the precision and accuracy of the present method were sufficiently reliable and reproducible. Thus, the requirements of sample analysis were satisfied in this study.

3.3.4. Extraction Recovery and Matrix Effect. The results of the absolute extraction recoveries and matrix effects in the above QC samples $(3,160$, and $480 \mathrm{ng} / \mathrm{mL}$ ) are presented in Table 2. The ranges of mean extraction recoveries were within $92.4-106.2 \%$ for MG and $94.3-105.0 \%$ for MG-Na, which suggested that the extraction procedure in this study was consistent and reproducible. The matrix effects of MG and MG-Na were between $93.7-100.5 \%$ and $95.2-101.4 \%$, respectively, in plasma sample in the above QC samples (3, 160 , and $480 \mathrm{ng} / \mathrm{mL}$ ), which indicated that the matrix effects were negligible in this method for the detection of plasma samples, as shown in Table 2.

3.3.5. Stability. The stability results of MG and MG-Na at QC samples $(3,160$, and $480 \mathrm{ng} / \mathrm{mL})$ in plasma sample are presented in Tables 3 and 4, respectively, under different storing and processing procedures. The results of short-term stability, long-term stability, and freeze-thaw stability showed that the RSD was less than $6.7 \%$ and the RE ranged from $-4.8 \%$ to $7.5 \%$, which suggested a good stability in this experiment. Thus, it was demonstrated that the MG and MG-Na were stable in rat plasma to allow for routine analysis as a part of the following pharmacokinetic analysis of MG and MG-Na in the present study.

3.3.6. Dilution Integrity. Dilution integrity is necessary when the concentration of analytes in the samples is expected to over the ULOQ. The dilution integrity was determined by analyzing 6 replicates of MG and MG-Na in Table S1. The RSD and RE of MG were less than $4.6 \%$ and ranged from $-1.5 \%$ to $4.2 \%$, respectively. The RSD and RE of MG-Na were less than $5.5 \%$ and ranged from $-1.7 \%$ to $3.0 \%$, respectively. The results were acceptable and conformed to the requirements of biological sample analysis, which showed that blank plasma dilution did not affect the detection of drug concentration and proved once again that endogenous substances in plasma did not interfere with the determination of drug concentration. In addition, the analyte concentration in the plasma samples was higher than that in the above ULOQ, which can be diluted adequately with drug-free blank plasma and reanalyzed by using any of the dilution factors. The above results suggested that pharmacokinetic samples described above the linearity range can be efficiently quantified up to the dilution of 600 -fold.

3.3.7. Carryover. In the current study, carryover was assessed via injection of processed drug-free blank samples followed by the ULOQ. The results of the carryover are shown in Table S2. No significant carryover from MG, MG-Na, and IS was observed when the blank plasma sample was detected subsequent to the above ULOQ. The carryover effects of analytes were less than $20 \%$ of the LLOQ $(1.0 \mathrm{ng} / \mathrm{mL})$ when the blank plasma sample was detected subsequent to ULOQ, which 
TABle 1: Precision and accuracy of MG and MG-Na in rat plasma $(x \pm s \mathrm{ng} / \mathrm{mL})$.

\begin{tabular}{|c|c|c|c|c|c|c|}
\hline \multirow{2}{*}{ Plasma concentration } & \multicolumn{3}{|c|}{ Intraday } & \multicolumn{3}{|c|}{ Interday } \\
\hline & Mean concentration & RSD (\%) & RE (\%) & Mean concentration & RSD (\%) & $\mathrm{RE}(\%)$ \\
\hline \multicolumn{7}{|l|}{ MG } \\
\hline 3 & $3.172 \pm 0.152$ & 4.7 & 4.5 & $2.933 \pm 0.118$ & 4.0 & -2.2 \\
\hline 160 & $166.357 \pm 10.674$ & 6.4 & 3.9 & $168.537 \pm 11.731$ & 6.9 & 5.3 \\
\hline 480 & $486.523 \pm 13.543$ & 2.9 & 1.4 & $483.545 \pm 23.848$ & 4.9 & 07 \\
\hline \multicolumn{7}{|l|}{ MG-Na } \\
\hline 3 & $3.124 \pm 0.107$ & 3.4 & 4.1 & $3.201 \pm 0.179$ & 5.6 & 6.7 \\
\hline 160 & $168.343 \pm 8.472$ & 5.0 & 5.2 & $172.498 \pm 10.549$ & 6.1 & 7.8 \\
\hline 480 & $491.573 \pm 10.456$ & 2.1 & 2.4 & $489.384 \pm 16.331$ & 3.3 & 2.0 \\
\hline
\end{tabular}

TABLE 2: Extraction recovery and matrix effects of MG and MG-Na in rat plasma $(x \pm s \mathrm{ng} / \mathrm{mL})$.

\begin{tabular}{|c|c|c|c|c|c|c|}
\hline \multirow{2}{*}{ Plasma concentration } & \multicolumn{3}{|c|}{ Extraction recovery rate } & \multicolumn{3}{|c|}{ Matrix effect } \\
\hline & Recovery rate (\%) & RSD (\%) & RE (\%) & Matrix effect (\%) & RSD (\%) & $\mathrm{RE}(\%)$ \\
\hline \multicolumn{7}{|l|}{$\mathrm{MG}$} \\
\hline 3 & $96.6 \pm 4.2$ & 4.2 & -3.4 & $97.1 \pm 3.4$ & 3.4 & -2.9 \\
\hline 160 & $103.5 \pm 2.7$ & 2.7 & 3.5 & $98.2 \pm 2.3$ & 2.3 & -1.8 \\
\hline 480 & $97.5 \pm 3.3$ & 3.3 & -2.5 & $98.5 \pm 1.7$ & 1.7 & -1.5 \\
\hline \multicolumn{7}{|l|}{$\mathrm{MG}-\mathrm{Na}$} \\
\hline 3 & $97.1 \pm 2.8$ & 2.8 & -2.9 & $98.3 \pm 3.1$ & 3.1 & -1.7 \\
\hline 160 & $98.6 \pm 1.1$ & 1.1 & -1.4 & $99.1 \pm 1.3$ & 1.3 & -0.9 \\
\hline 480 & $102.7 \pm 2.3$ & 2.3 & -2.7 & $98.2 \pm 2.4$ & 2.4 & -1.8 \\
\hline
\end{tabular}

TABLE 3: Stability of MG in rat plasma $(x \pm s \mathrm{ng} / \mathrm{mL})$.

\begin{tabular}{lccc}
\hline Plasma concentration & $\begin{array}{c}\text { Measured } \\
\text { concentration }\end{array}$ & RSD (\%) & RE (\%) \\
\hline Short-term stability & $3.166 \pm 0.192$ & 6.1 & 5.5 \\
3 & $153.591 \pm 9.592$ & 6.2 & -4.0 \\
160 & $4486.328 \pm 25.495$ & 5.2 & 1.3 \\
480 & & & \\
\hline Long-term stability & $3.147 \pm 0.201$ & 6.4 & 4.9 \\
3 & $169.553 \pm 11.295$ & 6.7 & 6.0 \\
160 & $494.472 \pm 31.491$ & 6.4 & 3.0 \\
480 & & & \\
Freeze-thaw stability & $3.127 \pm 0.112$ & 3.6 & 4.2 \\
3 & $154.212 \pm 6.521$ & 4.2 & -3.6 \\
160 & $473.351 \pm 17.381$ & 3.7 & -1.4 \\
480 & & &
\end{tabular}

suggested that carryover effect on samples can be negligible at or near the LLOQ in the UPLC analysis system including the injection needle, filter, switching valve, column, and guard column. Thus, the results showed that the carryover did not affect accuracy and precision during the analysis of the study plasma samples.

3.4. Analysis and Comparison of Pharmacokinetics of $M G$ and MG-Na. The above-validated UPLC-MS/MS method was successfully applied to the plasma comparative pharmacokinetic profiles of MG and MG-Na after a single oral administration at $100 \mathrm{mg} / \mathrm{kg}$ in rats in vivo, respectively. The mean concentration-time curves of $\mathrm{MG}$ and $\mathrm{MG}-\mathrm{Na}$ in plasma were analyzed by utilizing Drug and Statistics (DAS) 2.0 software to determine the compartment model, and the
TABle 4: Stability of MG-Na in rat plasma $(x \pm s \mathrm{ng} / \mathrm{mL})$.

\begin{tabular}{lccc}
\hline Plasma concentration & $\begin{array}{c}\text { Measured } \\
\text { concentration }\end{array}$ & RSD (\%) & RE (\%) \\
\hline Short-term stability & & & \\
3 & $3.053 \pm 0.121$ & 4.0 & 1.8 \\
160 & $171.937 \pm 9.376$ & 5.5 & 7.5 \\
480 & $496.593 \pm 15.118$ & 3.0 & 3.5 \\
\hline Long-term stability & & & \\
3 & $3.198 \pm 0.193$ & 6.0 & 6.6 \\
160 & $163.518 \pm 8.574$ & 5.2 & 2.2 \\
480 & $487.412 \pm 21.382$ & 4.4 & 1.5 \\
\hline Freeze-thaw stability & & & \\
3 & $3.209 \pm 0.214$ & 6.7 & 7.0 \\
160 & $152.298 \pm 8.418$ & 5.5 & -4.8 \\
480 & $469.552 \pm 19.317$ & 4.1 & -2.2 \\
\hline
\end{tabular}

results are shown in Figures 2 and S4. Our results suggested that the plasma concentration-time curves of MG and MG$\mathrm{Na}$ were in accord with the regulation of the two-compartment model, respectively. In order to further investigate the differences of pharmacokinetic profiles between MG and MG-Na, we systematically studied pharmacokinetic parameters of $\mathrm{MG}$ and $\mathrm{MG}-\mathrm{Na}$. The main pharmacokinetic parameters included the $K_{10}, t_{1 / 2}, K_{\mathrm{a}}, C_{\max }, T_{\max }, \mathrm{AUC}_{(0-t)}$, $\mathrm{AUC}_{(0-\infty)}, V_{1} / F, \mathrm{CL} / F$, and so on, and the results are shown in Table 5. Although the dosages of MG and MG-Na were equivalent, the significant statistical differences were observed in $\mathrm{AUC}_{(0-t)}, \mathrm{AUC}_{(0-\infty)}, \mathrm{K}_{10}, K_{\mathrm{a}}, C_{\text {max }}, T_{\text {max }}, V_{1} / F$, and $\mathrm{CL} / F$, while not in $t_{1 / 2}$ between the two groups. These results suggested that the pharmacokinetic processes of MG-Na in vivo were dramatically altered compared with those of MG in the study. 


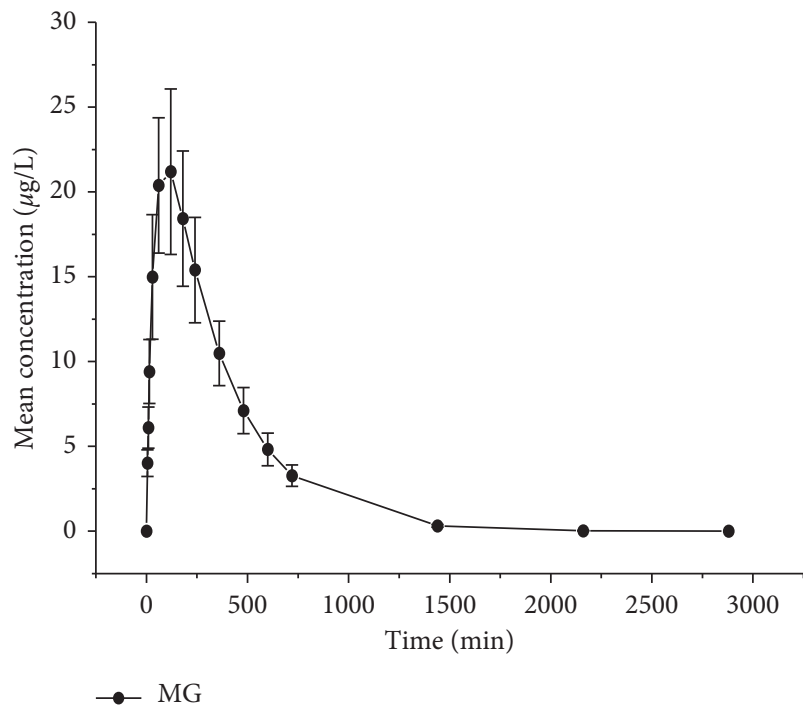

(a)

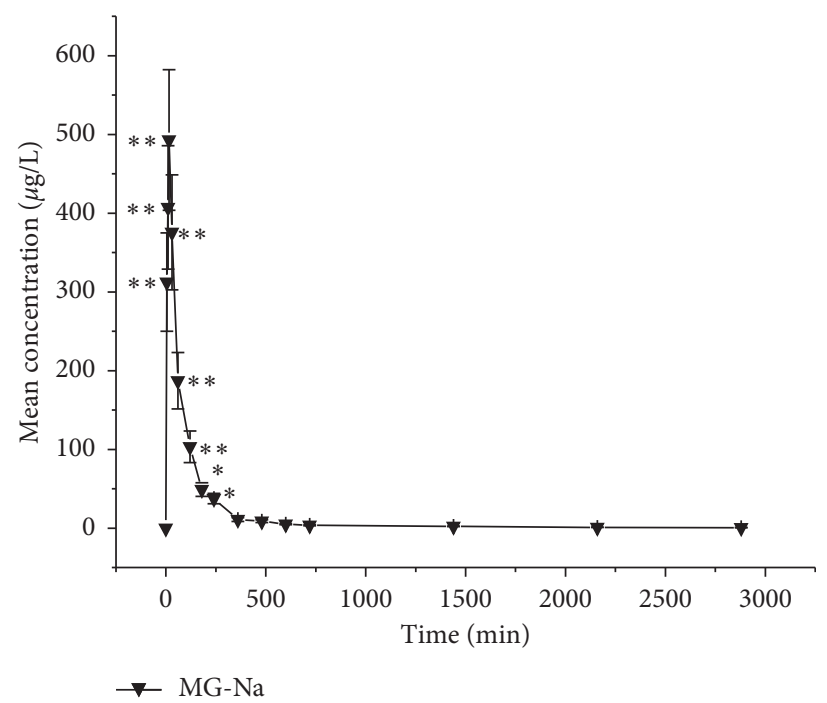

(b)

Figure 2: The plasma concentration-time curve of MG and MG-Na. The C-T curve after oral administration of MG (a) and the C-T curve after oral administration of MG-Na (b). ${ }^{*} P<0.05$ indicates significant differences from the MG; ${ }^{* *} P<0.01$ indicates highly significant differences from the MG.

As summarized in Figures 2 and S4, the significant differences were observed between MG and MG-Na in the mean plasma concentration-time curve. The blood concentration of MG is extremely low following oral administration in our study, and its application can be greatly restricted by its poor intestinal absorption [34], and the results are similar to those reported previously $[48,49]$. It is necessary for drugs to have a certain level of solubility to penetrate biomembranes. In our study, the solubility of MG-Na was greatly improved compared with that of the MG. So, MG-Na can have a good intestinal absorption in vivo. Here, the blood concentration of MG-Na is higher than that of the MG in our study. These differences suggest that the structural modification by a salification reaction induced a dramatically enhancement in the absorption of MG. Moreover, the absorption rate of MG-Na was significantly increased, and it can be detected by $5 \mathrm{~min}$ after oral administration and the concentration was highest at $15 \mathrm{~min}$. Then, the $C_{\max }$ and $T_{\max }$ were determined from the concentration-time curve. Our results showed that the $C_{\max }$ of $\mathrm{MG}(23.878 \pm 4.457 \mu \mathrm{g} / \mathrm{L})$ is extremely small compared to the administration dose $(100 \mathrm{mg} / \mathrm{kg})$, which is in agreement with the results from Hou et al. [25]. Several researchers have also reported that the oral bioavailability of mangiferin was extremely low in rats, which has been shown to be as low as 1.2\% [50]. The results from Tian et al. proved that the poor bioavailability of MG is possibly mainly attributed to its poor solubility and membrane permeability and, however, less correlated with transporters and metabolic enzymes (CYP450) [49]. However, the $C_{\max }$ of MG-Na $(496.867 \pm 79.472 \mu \mathrm{g} / \mathrm{L})$ was significantly increased by 20.8 -fold $(P<0.001)$ when compared with MG $(23.878 \pm 4.457 \mu \mathrm{g} / \mathrm{L})$, which indicated that the absorption of MG-Na was very good in rats in vivo. The results may be closely associated with high water-soluble property of MG-Na, which can avoid toxic organic solvents and solved the problems related to MG-Na administration. And, the above results are in good agreement with Dewland et al. and Valduga et al $[51,52]$. Moreover, the membrane permeability is another major reason for drug absorption in the intestinal tract, and MG-Na can effectively regulate it due to its good solubility. So, MG-Na can significantly improve the bioavailability by a salification reaction of $\mathrm{MG}$, and the increase of the bioavailability found for MG-Na can be very interesting pharmacologically.

The result of $T_{\max }$ in MG was $60.00 \mathrm{~min}$, and it is consistent with previous research results [49]. These results indicated that MG could be absorbed from the rat gastrointestinal tract and the hepatic first-pass effect may be one of the limitations of its health-promoting effects. To improve its bioavailability, new kinds of pharmaceutical preparations or other administration routes should be adopted. So, the structure of MG was modified to MG-Na by a salification reaction. As expected, this absorption rate of MG-Na was rapidly increased accompanied by an increase in the peak plasma concentration, and the $T_{\max }$ of MG-Na (15.00 min) was significantly reduced by 4 -fold $(P<0.01)$ compared with the MG group in rats in vivo. This is likely to be due to faster dissolution and absorption of MG-Na particles, as indicated by Dewland et al. [51]. The $K_{\mathrm{a}}$ of the MG-Na group $(0.717 \pm 0.1291 / \mathrm{min})$ was greatly increased to approximately 28.7 -fold $(P<0.01)$ when compared to the MG group $(0.025 \pm 0.0011 / \mathrm{min})$, which suggested that MG-Na was rapidly absorbed in rats in vivo. Additionally, the elimination constant $\left(K_{10}\right)$ for the MG-Na group $(0.016 \pm 0.0011 / \mathrm{min})$ was remarkably increased by 8 -fold $(P<0.01)$ when compared to the MG group $(0.002 \pm 0.0001 / \mathrm{min})$. The differences were not observed with regard to $t_{1 / 2}$ between MG group and MG-Na group $(P<0.05)$, of which result may be contributed by 


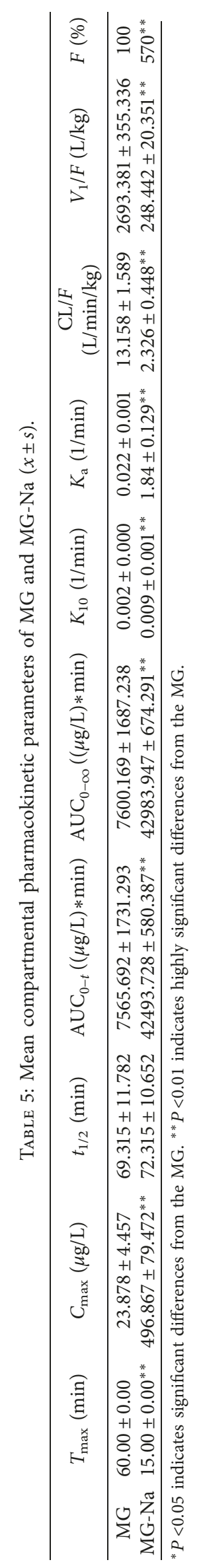


reducing $T_{\max }$ and increasing $K_{10}$, and indicated that MG-Na cannot intervene the hepatic metabolism by oral administration. The $V_{1} / F$ of the MG-Na group $(248.442 \pm 20.351 \mathrm{~L} / \mathrm{kg})$ was significantly reduced to approximately 10.8 -fold $(P<0.01)$ compared to the MG group $(2693.381 \pm 355.336 \mathrm{~L} /$ $\mathrm{kg})$. The CL/F of the MG-Na group $(2.326 \pm 0.448 \mathrm{~L} / \mathrm{min} / \mathrm{kg})$ was significantly reduced to approximately 5.7 -fold $(P<0.01)$ compared to the MG group $(13.158 \pm 1.589 \mathrm{~L} / \mathrm{min} / \mathrm{kg})$. The above results suggested the fact that it does not have the same bioavailability for MG-Na and MG.

As shown in Table 5, the pharmacokinetic parameters $\mathrm{AUC}_{(0-t)}$ and $\mathrm{AUC}_{(0-\infty)}$ were obtained in the above study. Meantime, the rapid absorption phase was observed from starting time to $T_{\max }$ and infinity, respectively. The results showed that the $\mathrm{AUC}_{(0-t)}$ of MG-Na $(42493.728 \pm 580.387 \mu \mathrm{g} /$ L-min) was 5.6-fold higher $(P<0.01)$ than that of MG $(7565.692 \pm 1731.293 \mu \mathrm{g} / \mathrm{L} \cdot \mathrm{min})$, and the $\mathrm{AUC}_{(0-\infty)}$ of MG-Na $(42983.947 \pm 674.291 \mu \mathrm{g} / \mathrm{L} \cdot \mathrm{min})$ was 5.7 -fold higher $(P<0.01)$ than that of MG $(7600.169 \pm 1687.238 \mu \mathrm{g} / \mathrm{L} \cdot \mathrm{min})$ in rats in vivo, which suggested an increase in the relative bioavailability of MG-Na. In the study, the increased $C_{\max }$ and reduced $\mathrm{CL} / \mathrm{F}$ values all contributed to the significantly enhanced $\mathrm{AUC}_{(0-t)}$ and $\mathrm{AUC}_{(0-\infty)}$ of the MG-Na group when compared with the MG group. These results indicated the MG-Na concentration remarkably increased over time in rats in vivo, and the relative bioavailability of MG-Na to MG was $570 \%\left(\mathrm{AUC}_{0-\infty(\mathrm{MG}-\mathrm{Na})} / \mathrm{AUC}_{0-\infty(\mathrm{MG})}\right)$, which suggested MG-Na could maintain the effective concentration, dissolution, and membrane permeability in rats in vivo for a long period of time.

Overall, big changes are being observed in the mean plasma concentration-time profiles and pharmacokinetic parameters between MG and MG-Na after a single oral administration, which suggested that the structural modification by a salification reaction of MG induced a remarkable enhancement in gastrointestinal absorption and relative bioavailability of MG by improving solubility and membrane permeability in the present study. Thus, the above pharmacokinetics study of MG-Na may be more helpful for the farther development and clinical study of MG-Na in the near future. Additionally, more research studies are needed to clarify the functional mechanisms of the oral relative bioavailability increase of MG-Na.

3.5. Safety. Single oral doses of MG or MG-Na $400 \mathrm{mg}$ were generally safe for healthy rat subjects when administered orally in the fed or fasted state (data not shown). No deaths, serious adverse events, or other significant adverse events were found during the study. At the same time, the MG and MG-Na have no safety concerns by the parameter assessment of behavior (walk and sleep), food, water and energy intake, hair, body weight, tissue weight, liver function (ALT, AST, and ALT/AST), liver histopathology, and feces and urine color.

In this study, the toxicity studies of MG-Na (such as $\mathrm{LD}_{50}$ and maximum tolerated dose (MTD)) were performed by gavage (data not shown). Here, mice rather than rats were used because it is scientifically documented that lethal dose data collected from mice might be more appropriate to anticipate the toxic effects in human beings $[53,54]$. The $\mathrm{LD}_{50}$ results showed that the mice were not sacrificed when the dosage regimen for MG-Na was based on the highest dose level given $(4000 \mathrm{mg} / \mathrm{kg}$ ). So, we performed the maximum tolerated dose (MTD, $12000 \mathrm{mg} / \mathrm{kg}$ ). During 14 days of the MTD evaluation period, it was observed that appearance, behavior, food intake, water intake, feces, and urine were normal with no significant variations in body weight, and no deaths occurred that were related to the test substance. The results suggested normal processing of metabolism involving carbohydrates, proteins, and fat which play a key role in the physiological functions in vivo. At the end of the experiment, there were no lesions found on macroscopic observation of the brain, heart, liver, spleen, lungs, and kidney by comparison with the normal control group. Statistically, no significant variations were found in organ-to-body weight index of mice in the MG-Na group compared to the control group. Overall, MG-Na caused neither morbidity nor death with no $\mathrm{LD}_{50}$ and unlimited MTD, indicating its safety in use.

The above results suggested that MG-Na after oral administration is safe and well tolerated and has no toxicity, which provides a certain security guarantee for MG-Na study and development in the near future.

\section{Conclusions}

The numerous clinical experiments show that the absorption, distribution, metabolism, excretion, and toxicity process of drugs are important indicators of druggability. According to the physical properties of drug candidates, the drug structure will be designed rationally and this study illustrates this fact by transforming poorly soluble MG into MG-Na with good solubility. The result of main pharmacokinetic comparisons of MG and MG-Na showed that the pharmacokinetic parameters of MG and MG-Na have remarkable differences, which suggested that the salification reaction of MG can effectively enhance gastrointestinal absorption and relative bioavailability by improving solubility and membrane permeability. To our knowledge, this is the first report demonstrating pharmacokinetic comparisons of mangiferin and mangiferin monosodium salt in rat plasma by UPLC-MS/MS. Simultaneously, the resulting pharmacokinetic data can aid the understanding of the safety of MG-Na and lay the foundation for future drug research.

\section{Data Availability}

The data used to support the findings of this study are included within the article. Data are available from the corresponding author (Chengyan Zhou, xuefanone@163.com) for researchers who meet the criteria for access to confidential data.

\section{Conflicts of Interest}

The authors declare no conflicts of interest. 


\section{Authors' Contributions}

C.Y.Z. designed the experiments and reviewed the manuscript before submission. G.H.B. performed the data analysis and discussed the results. C.M.Q. performed analyses and drafted the manuscript. L.M.R. performed the research. C.B.H. substantially contributed to the literature search and statistical analyses. All authors read and approved the final manuscript for publication.

\section{Acknowledgments}

This research was supported by the project from the Science and Technology Research and Development Guidance Plan of Baoding City (no. 18ZF121) and College Students Innovation and Entrepreneurship Training Program of Hebei University (no. 2018280).

\section{Supplementary Materials}

The supplementary materials consist of four figures and three tables to further clarify the method validation, synthesis procedures for MG-Na, and pharmacokinetic comparison results of $\mathrm{MG}$ and $\mathrm{MG}-\mathrm{Na}$ in rat plasma. (Supplementary Materials)

\section{References}

[1] A. Matkowski, P. Kus, E. Goralska, and D. Wozniak, "Mangiferin-a bioactive xanthonoid, not only from mango and not just antioxidant," Mini Reviews in Medicinal Chemistry, vol. 13, no. 3, pp. 439-455, 2013.

[2] D. K. Chakrabarti and S. Ghosal, "The disease cycle of mango malformation induced by Fusarium moniliforme var. subglutinans and the curative effects of mangiferin-metal chelates," Journal of Phytopathology, vol. 125, no. 3, pp. 238-246, 2010.

[3] R. Ochocka, A. Hering, J. Stefanowicz-Hajduk et al., "The effect of mangiferin on skin: penetration, permeation and inhibition of ECM enzymes," PLoS One, vol. 12, no. 7, Article ID e0181542, 2017.

[4] D. Ahsana, F. Shaheen, N. Sabira et al., "Analgesic and antioxidant activity of mangiferin and its derivatives: the structure activity relationship," Biological \& Pharmaceutical Bulletin, vol. 28, no. 4, pp. 596-600, 2005.

[5] C. Zhou, G. Li, Y. Li et al., "A high-throughput metabolomic approach to explore the regulatory effect of mangiferin on metabolic network disturbances of hyperlipidemia rats," Molecular Biosystems, vol. 11, no. 2, pp. 418-433, 2015.

[6] M. Imran, M. S. Arshad, M. S. Butt et al., "Mangiferin: a natural miracle bioactive compound against lifestyle related disorders," Lipids in Health \& Disease, vol. 16, no. 1, pp. 84-100, 2017.

[7] Jyotshna, P. Khare, and K. Shanker, "Mangiferin: a review of sources and interventions for biological activities," Biofactors, vol. 42, no. 5, pp. 504-514, 2016.

[8] L. M. Acevedo, A. I. Raya, J. M. Martínez-Moreno et al., "Mangiferin protects against adverse skeletal muscle changes and enhances muscle oxidative capacity in obese rats," PLoS One, vol. 12, no. 3, Article ID e0173028, 2017.

[9] X. Wang, L. Gao, H. Lin et al., "Mangiferin prevents diabetic nephropathy progression and protects podocyte function via autophagy in diabetic rat glomeruli," European Journal of Pharmacology, vol. 824, pp. 170-178, 2018.

[10] N. D. Wong, Y. Zhao, R. G. W. Quek et al., "Residual atherosclerotic cardiovascular disease risk in statin-treated adults: the multi-ethnic study of atherosclerosis," Journal of Clinical Lipidology, vol. 11, no. 5, pp. 1223-1233, 2017.

[11] F. Gold-Smith, A. Fernandez, and K. Bishop, "Mangiferin and cancer: mechanisms of action," Nutrients, vol. 8, no. 7, pp. 396-410, 2016.

[12] H. Ma, H. Chen, L. Sun, L. Tong, and T. Zhang, "Improving permeability and oral absorption of mangiferin by phospholipid complexation," Fitoterapia, vol. 93, no. 3, pp. 54-61, 2014.

[13] C. Chu, M. Li, J. Li, and C. Zhou, "The protective effects of mangiferin on metabolic and organs functions in the adolescent rat model of alcohol abuse," Journal of Functional Foods, vol. 46, pp. 90-100, 2018.

[14] W. J. Xiao, J. Hou, J. Ma et al., "Mangiferin loaded magnetic pcec microspheres: preparation, characterization and antitumor activity studies in vitro," Archives of Pharmacal Research, vol. 37, no. 10, Article ID 25266232, 7 pages, 2014.

[15] R. K. Bulugonda, K. A. Kumar, D. Gangappa et al., "Mangiferin from Pueraria tuberosa reduces inflammation via inactivation of NLRP3 inflammasome," Scientific Reports, vol. 7, no. 3, Article ID 42683, 2017.

[16] S. Mahendran, S. Badami, S. Ravi et al., "Synthesis and evaluation of analgesic and anti-inflammatory activities of most active free radical scavenging derivatives of mangiferin," Astronomy \& Astrophysics, vol. 399, no. 2, pp. 519-523, 2014.

[17] W. Guo, S. Du, Y. L. Lin et al., "Structural and computational insights into the enhanced solubility of dipfluzine by complexation: salt and salt-cocrystal," New Journal of Chemistry, vol. 42, no. 18, pp. 15068-15078, 2018.

[18] Z. Li, J. Wang, Y. Zhou et al., "Lead compound optimization strategy (3)-Structure modification strategies for improving water solubility," Yao Xue Xue Bao=Acta Pharmaceutica Sinica, vol. 49, no. 9, pp. 1238-1247, 2014.

[19] Z.-H. Zhang, Q. Zhang, Q.-Q. Zhang et al., "From a binary salt to salt co-crystals of antibacterial agent lomefloxacin with improved solubility and bioavailability," Acta Crystallographica Section B Structural Science, Crystal Engineering and Materials, vol. 71, no. 4, pp. 437-446, 2015.

[20] M. Ghulam, K. A. Shujaat, M. Najam-ul-Haq, and I. Hussain, "Comparative evaluation of various solubility enhancement strategies for furosemide," Pakistan Journal of Pharmaceutical Sciences, vol. 27, no. 4, pp. 963-973, 2014.

[21] M. Mabuchi, T. Shimizu, M. Ueda et al., "Improving the bioavailability and anticancer effect of the PCA-1/ALKBH3 inhibitor HUHS015 using sodium salt," In Vivo, vol. 29, no. 1, pp. 39-43, 2015.

[22] M. X. Liao, B. C. Chuang, Q. Zhu et al., "Preclinical absorption, distribution, metabolism, excretion, and pharmacokinetics of A novel selective inhibitor of breast cancer resistance protein (BCRP)," xenobiotica; The Fate of Foreign Compounds in Biological Systems, vol. 48, no. 5, pp. 1-40, 2017.

[23] B. Hong, H. Chen, J. Han et al., "A study of 11-[3H]-Tetrodotoxin absorption, distribution, metabolism and excretion (ADME) in adult sprague-dawley rats," Marine Drugs, vol. 15, no. 6, pp. 159-172, 2017.

[24] K. Yoshinari and K. Yamashita, "Analytical chemistry for ADMET research: recent advances and future directions in LC-MS/MS and omics approaches," Drug Metabolism and Pharmacokinetics, vol. 31, no. 1, pp. 1-2, 2016. 
[25] S. Hou, F. Wang, Y. Li et al., "Pharmacokinetic study of mangiferin in human plasma after oral administration," Food Chemistry, vol. 132, no. 1, pp. 289-294, 2012.

[26] M. Shi, L. Yin, L. Cai et al., "LC-MS/MS method for the quantitation of cefotetan in human plasma and its application to pharmacokinetic study," Chemical Research in Chinese Universities, vol. 30, no. 6, pp. 900-904, 2014.

[27] L. Yin, Y. H. Zhang, S. Zhao et al., "Rapid quantification of astilbin in rat plasma by liquid chromatography-tandem mass spectrometry and its application to pharmacokinetic study," Chemical Research in Chinese Universities, vol. 29, no. 6, pp. 1078-1082, 2014.

[28] L. Wang, D. K. Phan, N. Syn et al., "A sensitive liquid chromatography-tandem mass spectrometry method for the determination of nimbolide in mouse serum: application to a preclinical pharmacokinetics study," Pharmaceutics, vol. 10, no. 3, pp. 123-134, 2018.

[29] K. Lan and W. Jia, "An integrated metabolomics and pharmacokinetics strategy for multi-component drugs evaluation," Current Drug Metabolism, vol. 11, no. 1, pp. 105-114, 2010.

[30] Y. F. Yuan and J. G. Deng, "Process for preparing mangiferin monosodium salt," Chinese Journal of Hospital Pharmacy, vol. 28, no. 3, pp. 181-183, 2008.

[31] L. V. Christensen, M. Loftager, F. Rode, H. M. Nielsen, M. Kreilgaard, and M. S. Larsen, "Impact of capacity-limited binding on recombinant factor VIII and von Willebrand factor pharmacokinetics in hemophilia a rats," Journal of Thrombosis and Haemostasis, vol. 17, no. 6, pp. 964-974, 2019.

[32] Y. Xu, Q. D. Zhang, P. Li et al., "Nicotine pharmacokineticsin rat brain and blood by simultaneous microdialysis, stableisotope labeling, and UHPLC-HRMS: determination of nicotine metabolites," Analytical Chemistry, vol. 91, no. 4, pp. 2916-2922, 2019.

[33] L. Lai, L. C. Lin, J. H. Li, and T. H. Tsai, "Pharmacokinetic study of free mangiferin in rats by microdialysiscoupled with microbore high-performance liquid chromatography and tandem mass spectrometry," Journal of Chromatography A, vol. 987, no. 1-2, pp. 367-374, 2014.

[34] F. Cai, L. Sun, S. H. Gao, Q. Zhan et al., "An improved LC-MS/ MS method for the determination of mangiferin in rat plasma and its application in nonlinear pharmacokinetics," Die Pharmazie, vol. 69, no. 3, pp. 168-172, 2014.

[35] M. R. Li, C. X. Wu, H. B. Guo, C. Chu, M. Hu, and C. Zhou, "Mangiferin improves hepatic damage-associated molecular patterns, lipid metabolic disorder and mitochondrial dysfunction in alcohol hepatitis rats," Food \& Function, vol. 10, no. 6, pp. 3514-3534, 2019.

[36] A. K. Kammalla, M. K. Ramasamy, J. Inampudi, G. P. Dubey, A. Agrawal, and I. Kaliappan, "Comparative pharmacokinetic study of mangiferin after oral administration of pure mangiferin and us patented polyherbal formulation to rats," AAPS PharmSciTech, vol. 16, no. 2, pp. 250-258, 2014.

[37] Y. L. Hou, S. J. Fan, H. Zhang et al., "Pharmacokinetic study of mangiferin in rat plasma and retina using high-performance liquid chromatography," Molecular Vision, vol. 16, no. 178, pp. 1659-1668, 2010.

[38] J. Yang, Z. Sun, D. L. Li et al., “A novel liquid chromatography orbitrap mass spectrometry method with full scan for simultaneous determination of multiple bioactive constituents of shenkang injection in rat tissues: application to tissue distribution and pharmacokinetic studies," Biomedical Chromatography, vol. 32, no. 10, Article ID e4306, 2018.
[39] C. Qi, Q. Cai, P. Zhao et al., "The metal-organic framework MIL-101(Cr) as efficient adsorbent in a vortex-assisted dispersive solid-phase extraction of imatinib mesylate in rat plasma coupled with ultra-performance liquid chromatography/mass spectrometry: application to a pharmacokinetic study," Journal of Chromatography A, vol. 1449, pp. 30-38, 2016.

[40] L. H. Zuo, Z. Sun, Z. H. Wang, D. L. Ding et al., “Tissue distribution profiles of multiple major bioactive components in rats after intravenous administration of Xuebijing injection by UHPLC-Q-Orbitrap HRMS," Biomedical Chromatography, vol. 33, no. 2, Article ID e4400, 2018.

[41] J. S. Nancy, A. M. Ray, A. M. Palma et al., "Safety evaluation of oleic-rich triglyceride oil produced by a heterotrophic microalgal fermentation process," Food and Chemical Toxicology, vol. 65, pp. 301-311, 2014.

[42] P. Tong, C. Wu, X. Wang et al., "Development and assessment of a complete-detoxication strategy for Fuzi (lateral root of Aconitum carmichaeli) and its application in rheumatoid arthritis therapy," Journal of Ethnopharmacology, vol. 146, no. 2, pp. 562-571, 2013.

[43] S. Suryawanshi, R. K. Asthana, and R. C. Gupta, "Simultaneous estimation of mangiferin and four secoiridoid glycosides in rat plasma using liquid chromatography tandem mass spectrometry and its application to pharmacokinetic study of herbal preparation," Journal of Chromatography B, vol. 858, no. 1-2, pp. 211-219, 2007.

[44] Y. Liu, J. Sun, H. Lian et al., "Determination of paclitaxel in hyaluronic acid polymeric micelles in rat blood by protein precipitation-micelle breaking method: application to a pharmacokinetic study," Journal of Chromatography B, vol. 935, no. 18, pp. 10-15, 2013.

[45] S. Dittakavi, R. K. Jat, and R. Mullangi, "Quantitative analysis of enasidenib in dried blood spots of mouse blood using an increased-sensitivity LC-MS/MS method: application to a pharmacokinetic study," Biomedical Chromatography, vol. 33, no. 6, Article ID e4491, 2019.

[46] Y. Zeng, S. Li, X. Wang, T. Gong, X. Sun, and Z. Zhang, "Validated LC-MS/MS method for the determination of scopoletin in rat plasma and its application to pharmacokinetic studies," Molecules, vol. 20, no. 10, pp. 18988-19001, 2015.

[47] Y. Liu, F. Xu, X. Zeng et al., "Application of a liquid chromatography/tandem mass spectrometry method to pharmacokinetic study of mangiferin in rats," Journal of Chromatography B, vol. 878, no. 32, pp. 3345-3350, 2010.

[48] H. Liu, B. Wu, G. Pan et al., "Metabolism and pharmacokinetics of mangiferin in conventional rats, pseudo-germ-free rats, and streptozotocin-induced diabetic rats," Drug Metabolism and Disposition, vol. 40, no. 11, pp. 2109-2118, 2012.

[49] X. Tian, Z. Xu, Z. Li et al., "Pharmacokinetics of mangiferin and its metabolite-norathyriol, Part 2: influence of UGT, CYP450, P-gp, and enterobacteria and the potential interaction in Rhizoma Anemarrhenae decoction with timosaponin B2 as the major contributor," Biofactors, vol. 42, no. 5, pp. 545-555, 2016.

[50] D. Han, C. Chen, C. Zhang, Y. Zhang, and X. Tang, "Determination of mangiferin in rat plasma by liquid-liquid extraction with UPLC-MS/MS," Journal of Pharmaceutical and Biomedical Analysis, vol. 51, no. 1, pp. 260-263, 2010.

[51] P. M. Dewland, S. Reader, and P. Berry, "Bioavailability of ibuprofen following oral administration ostandard ibuprofen, sodium ibuprofen or ibuprofen acid incorporating poloxamer 
in healthy volunteers," BMC Clinical Pharmacology, vol. 9, no. 9, pp. 19-28, 2009.

[52] C. J. Valduga, G. P. Leonardo, D. A. Maria et al., "Synthesis of sodium 4-[5-(4-hydroxy-3- methoxyphenyl)-3-oxo-penta1,4-dienyl]-2-methoxy-phenolate and pharmacologic tests in vitro and in vivo," Cancer Research, vol. 69, no. 9, pp. 18-22, 2009.

[53] U. Saleem, S. Amin, B. Ahmad, H. Azeem, F. Anwar, and S. Mary, "Acute oral toxicity evaluation of aqueous Ethanolic extract of Saccharum munja Roxb. roots in albino mice as per OECD 425 TG," Toxicology Reports, vol. 4, pp. 580-585, 2017.

[54] E. Walum, M. Nilsson, C. Clemedson, and B. Ekwall, "The meic program and its implications for the prediction of acute human systemic toxicity," Alternative Methods in Toxicology, vol. 11, pp. 275-282, 1995. 

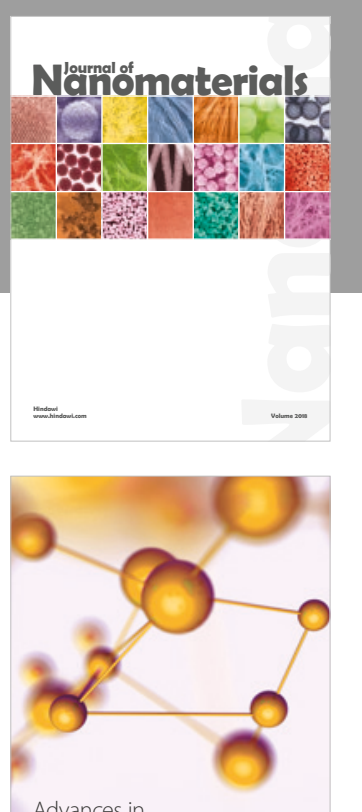

Physical Chemistry
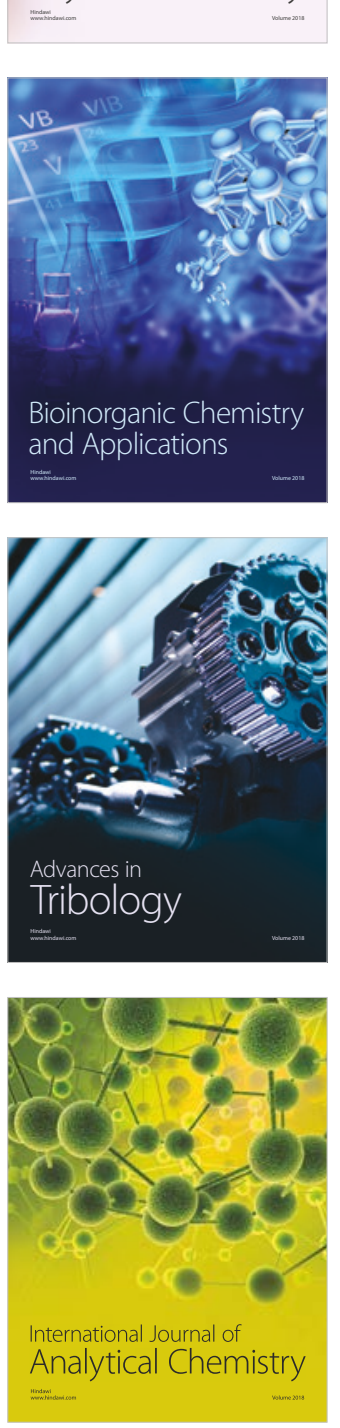

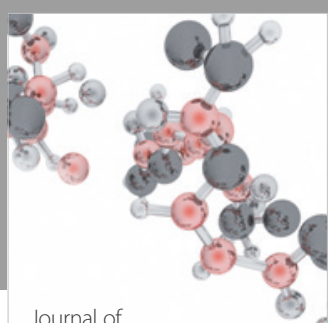

Analytical Methods

in Chemistry

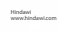

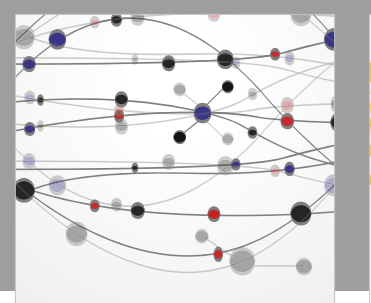

The Scientific World Journal

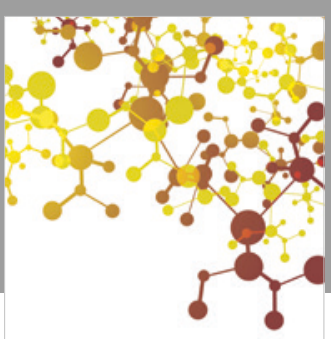

Journal of

Applied Chemistry
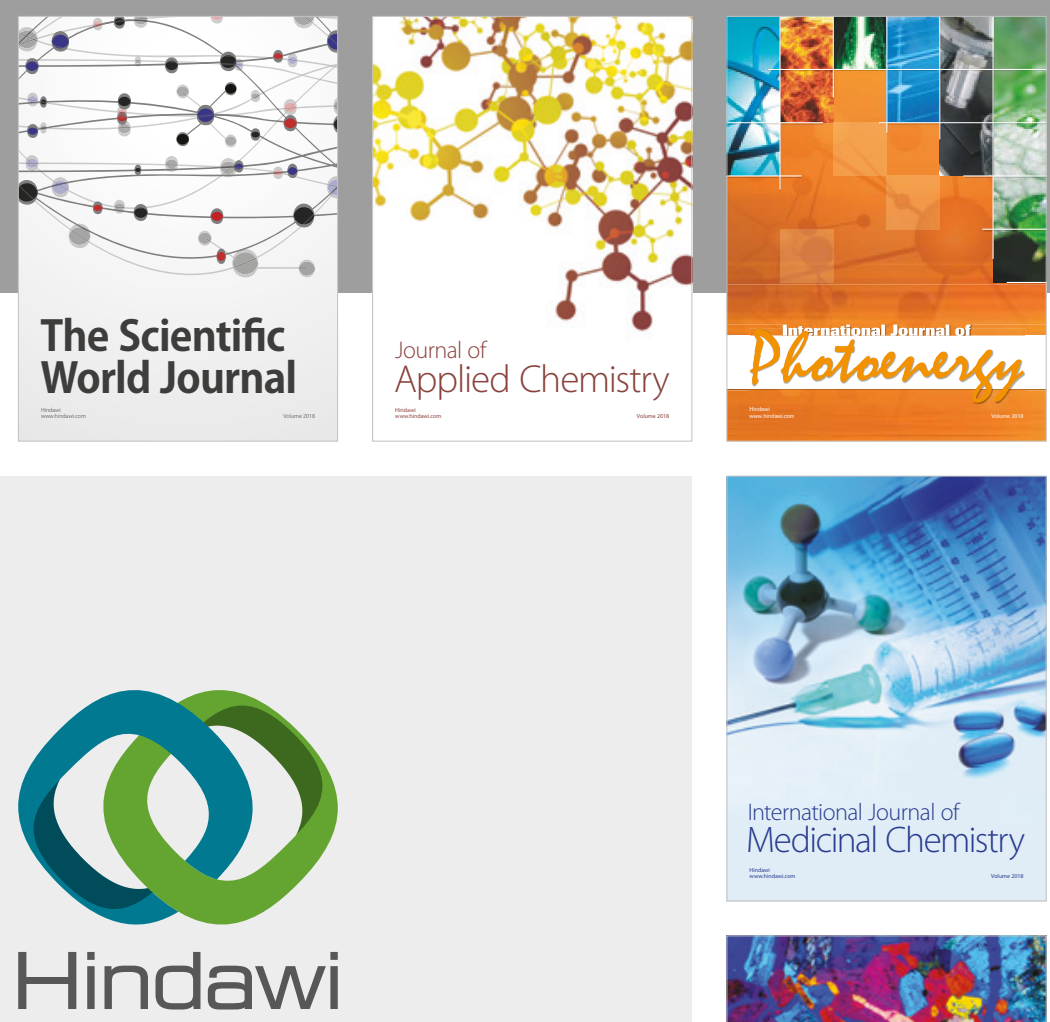

Submit your manuscripts at

www.hindawi.com
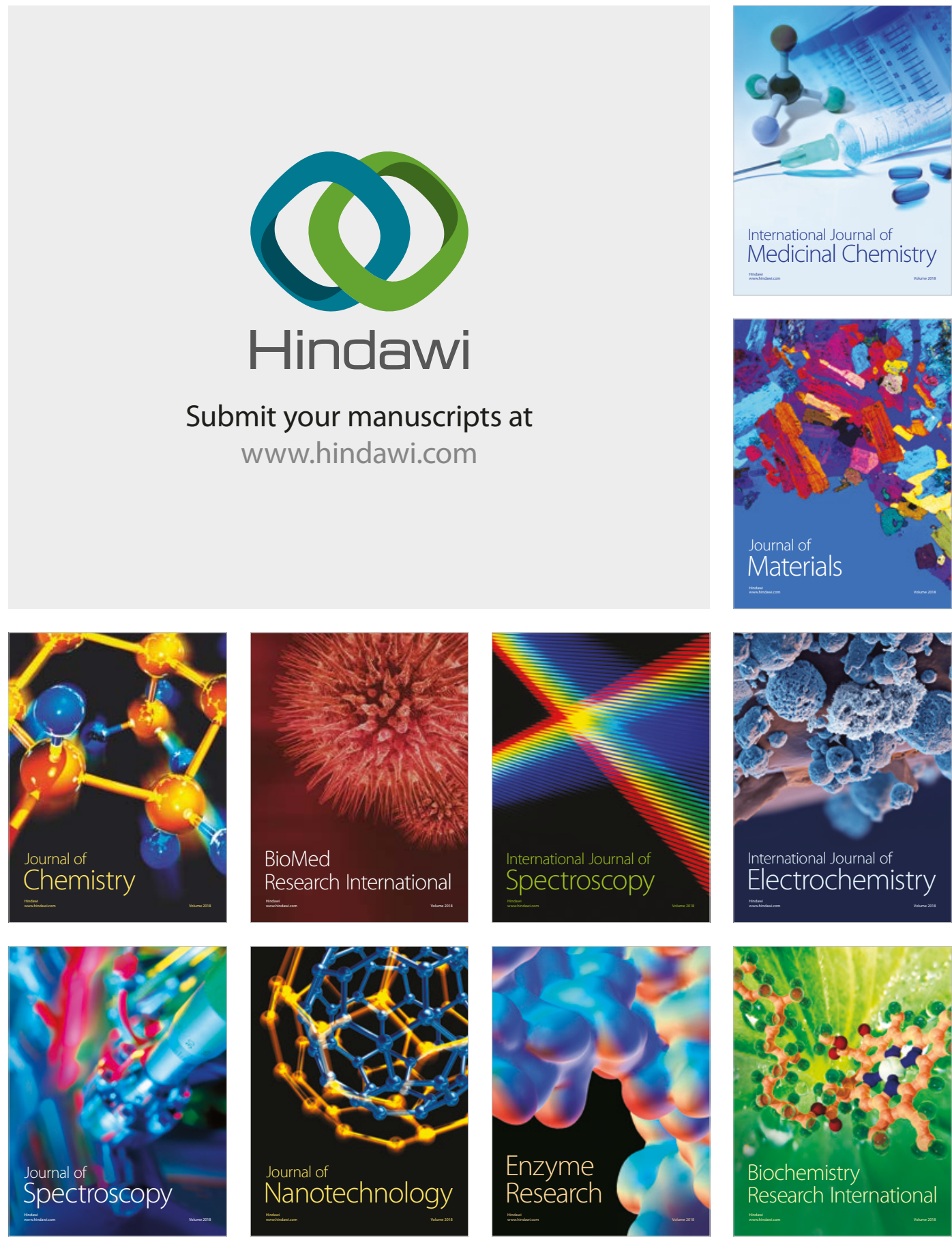
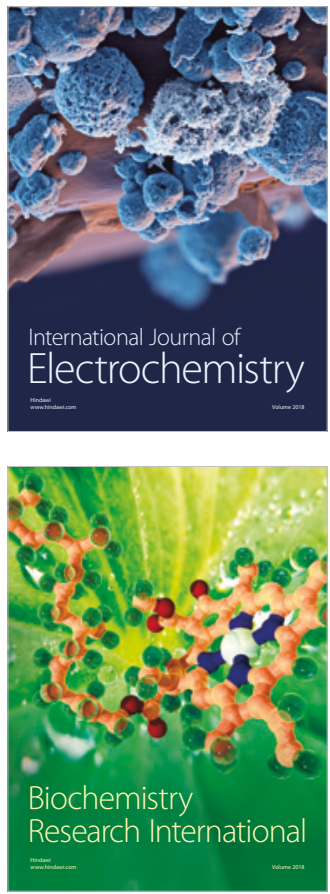